\title{
Electrical compensation and cation vacancies in Al rich Si-doped AIGaN
}

\section{Prozheev, I.}

2020-10-05

Prozheev , I , Mehnke , F , Wernicke , T , Kneissl , M \& Tuomisto , F 2020 , ' Electrical compensation and cation vacancies in Al rich Si-doped AIGaN ' , Applied Physics Letters , vol. 117 , no. 14 , 142103 . https://doi.org/10.1063/5.0016494

http://hdl.handle.net/10138/334903

https://doi.org/10.1063/5.0016494

unspecified

publishedVersion

Downloaded from Helda, University of Helsinki institutional repository.

This is an electronic reprint of the original article.

This reprint may differ from the original in pagination and typographic detail.

Please cite the original version. 


\section{Electrical compensation and cation vacancies in Al rich Si-doped AIGaN}

Cite as: Appl. Phys. Lett. 117, 142103 (2020); https://doi.org/10.1063/5.0016494

Submitted: 04 June 2020 . Accepted: 19 September 2020 . Published Online: 06 October 2020

I. Prozheev (D), F. Mehnke (D), T. Wernicke (D), M. KneissI (D), and F. Tuomisto (D)

\section{COLLECTIONS}

Paper published as part of the special topic on Ultrawide Bandgap Semiconductors
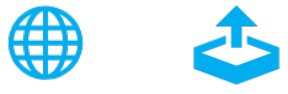

\section{ARTICLES YOU MAY BE INTERESTED IN}

$\mathrm{N}$-polar GaN/AIN resonant tunneling diodes

Applied Physics Letters 117, 143501 (2020); https://doi.org/10.1063/5.0022143

Milliwatt power $233 \mathrm{~nm}$ AIGaN-based deep UV-LEDs on sapphire substrates

Applied Physics Letters 117, 111102 (2020); https://doi.org/10.1063/5.0015263

Complexes and compensation in degenerately donor doped GaN

Applied Physics Letters 117, 102109 (2020); https://doi.org/10.1063/5.0013988

\section{Meet the Next Generation of Quantum Analyzers And Join the Launch Event on November 17th}

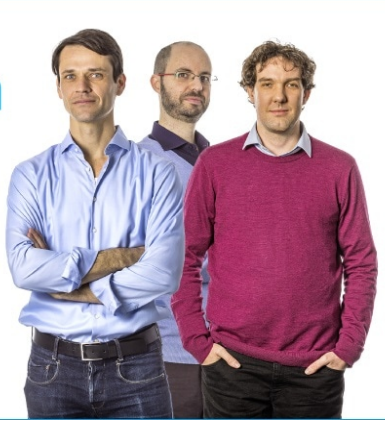

\section{Register now}

Zurich $\checkmark$ Instruments 


\title{
Electrical compensation and cation vacancies in Al rich Si-doped AlGaN
}

\author{
Cite as: Appl. Phys. Lett. 117, 142103 (2020); doi: 10.1063/5.0016494 \\ Submitted: 4 June 2020 - Accepted: 19 September 2020 . \\ Published Online: 6 October 2020
}

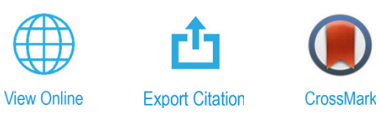

\author{
I. Prozheev, ${ }^{1,2, a)}$ (D) F. Mehnke, ${ }^{3,4}$ (D) T. Wernicke, ${ }^{4}$ (D) M. Kneissl, ${ }^{4}$ (D) and F. Tuomisto ${ }^{1,2}$ (D)
}

\begin{abstract}
AFFILIATIONS
'Department of Physics and Helsinki Institute of Physics, University of Helsinki, P.O. Box 43, Fl-00014 Helsinki, Finland

${ }^{2}$ Department of Applied Physics, Aalto University, P.O. Box 15100, Fl-00076 Espoo, Finland

${ }^{3}$ School of Electrical and Computer Engineering, Georgia Institute of Technology, 777 Atlantic Drive, Atlanta, Georgia 30332, USA

${ }^{4}$ Institute of Solid State Physics, Technische Universität Berlin, Hardenbergstr. 36, EW 6-1, 10623 Berlin, Germany
\end{abstract}

Note: This paper is part of the Special Topic on Ultrawide Bandgap Semiconductors.

a) Author to whom correspondence should be addressed: igor.prozheev@helsinki.fi

\begin{abstract}
We report positron annihilation results on vacancy defects in Si-doped $\mathrm{Al}_{0.90} \mathrm{Ga}_{0.10} \mathrm{~N}$ alloys grown by metalorganic vapor phase epitaxy. By combining room temperature and temperature-dependent Doppler broadening measurements, we identify negatively charged in-grown cation vacancies in the concentration range from below $1 \times 10^{16} \mathrm{~cm}^{-3}$ to $2 \times 10^{18} \mathrm{~cm}^{-3}$ in samples with a high C content, strongly correlated with the Si doping level in the samples ranging from $1 \times 10^{17} \mathrm{~cm}^{-3}$ to $7 \times 10^{18} \mathrm{~cm}^{-3}$. On the other hand, we find predominantly neutral cation vacancies with concentrations above $5 \times 10^{18} \mathrm{~cm}^{-3}$ in samples with a low $\mathrm{C}$ content. The cation vacancies are important as compensating centers only in material with a high $\mathrm{C}$ content at high Si doping levels.
\end{abstract}

Published under license by AIP Publishing. https://doi.org/10.1063/5.0016494

AlGaN alloys are semiconductor materials essential for the development of deep ultraviolet (UV) light emitting diodes (LEDs) and laser diodes (LDs). Such devices are highly demanded in a wide range of applications, including gas sensing, medical diagnostics, UV-light treatment, and detection and identification in biophysics. ${ }^{1}$ The main advantages of AlGaN-based devices over conventional UV sources, such as mercury lamps, are lower operating voltages, compact size, and adjustable emission wavelengths. ${ }^{2}$ The performance of devices based on AlGaN alloys emitting light shorter than $240 \mathrm{~nm}$ suffers from limited $n$-type conductivity of the Si-doped current spreading layers due to the high $\mathrm{Al}$ content $>80 \%$. ${ }^{3,4}$ The conductivity is limited not only by the increasing dopant ionization energy and formation of a stable DX center ${ }^{5,6}$ but potentially also by the formation of cation vacancy defects ${ }^{7} \mathrm{~V}_{\text {III }}$ that are known to act as compensating acceptors in $n$-type GaN and AlN..$^{8-11}$ These defects can be identified and quantified with the use of positron annihilation spectroscopy, a characterization technique with selective sensitivity to neutral and negative vacancy type defects as well as negatively charged non-open volume defects. ${ }^{1}$

In this Letter, we investigate the influence of growth conditions of Si-doped $\mathrm{Al}_{0.90} \mathrm{Ga}_{0.10} \mathrm{~N}$ alloys grown by metalorganic vapor phase epitaxy (MOVPE) on the occurrence of compensating point defects such as $\mathrm{C}$ impurities and cation vacancies. We find that $\mathrm{C}$ impurities are the dominant compensation mechanism for Si concentrations up to $5 \times 10^{18} \mathrm{~cm}^{-3}$. Depending on the growth conditions, at a higher $\mathrm{Si}$ concentration, either negatively charged cation vacancies or Si DX centers emerge as the important compensation mechanism of the $n$-type doping. These conclusions are based on positron annihilation spectroscopy studies, combining room-temperature and temperaturedependent Doppler broadening measurements on a set of 10 Si-doped $\mathrm{Al}_{0.90} \mathrm{Ga}_{0.10} \mathrm{~N}$ samples. Based on our findings, it would appear that the highest $n$-type conductivity could be achieved by optimizing the $\mathrm{Si}$ doping level at mid $-10^{18} \mathrm{~cm}^{-3}$ and the growth conditions with a high $\mathrm{V} / \mathrm{III}$ ratio, low growth rate, and low $\mathrm{C}$ content, resulting in electrically inactive cation vacancy defects.

The samples were grown by MOVPE in an Aixtron $3 \times 2$ in. $^{2}$ close-coupled showerhead reactor on [0001] oriented epitaxially laterally overgrown (ELO) AlN/sapphire with a miscut of $0.1^{\circ}$ towards the [1-100] sapphire direction. The TDD of the ELO AlN/sapphire is $1.5 \times 10^{9} \mathrm{~cm}^{-2} \cdot{ }^{13,14}$ The layer structure consists of a $400 \mathrm{~nm}$ thick AlN buffer layer, a $25 \mathrm{~nm}$ thick $\mathrm{AlN}$ to $\mathrm{Al}_{0.90} \mathrm{Ga}_{0.10} \mathrm{~N}$ graded transition layer, $100 \mathrm{~nm}$ undoped $\mathrm{Al}_{0.90} \mathrm{Ga}_{0.10} \mathrm{~N}$, and $980 \mathrm{~nm}$ to $1400 \mathrm{~nm} \mathrm{Si}$ doped $\mathrm{Al}_{0.90} \mathrm{Ga}_{0.10} \mathrm{~N}{ }^{15}$ The composition of the samples was determined under consideration of the layer strain state by high resolution 
TABLE I. The measured resistivity $\rho$ and concentrations of $\mathrm{Si}, \mathrm{H}$, oxygen, and $\mathrm{C}$ impurities together with the estimated concentrations of the $\mathrm{V}_{\mathrm{III}}$ vacancies in the AIGaN:Si samples.

\begin{tabular}{|c|c|c|c|c|c|c|}
\hline Sample & $\rho, \Omega \cdot \mathrm{cm}$ & {$[\mathrm{Si}], 10^{17} \mathrm{~cm}^{-3}$} & {$[\mathrm{H}], 10^{17} \mathrm{~cm}^{-3}$} & {$[\mathrm{O}], 10^{17} \mathrm{~cm}^{-3}$} & [C] $10^{17} \mathrm{~cm}^{-3}$ & [VIII], $10^{17} \mathrm{~cm}^{-3}$ \\
\hline $\mathrm{H} 1$ & $>13.4$ & 11 & 5 & 3 & 20 & $<0.1$ \\
\hline $\mathrm{H} 2$ & 6.63 & 21 & 5 & 3 & 20 & 2 \\
\hline H3 & 1.90 & 35 & 5 & 3 & 20 & 6 \\
\hline $\mathrm{H} 4$ & 0.99 & 54 & 5 & 3 & 20 & 10 \\
\hline H5 & 0.61 & 70 & 5 & 3 & 20 & 20 \\
\hline $\mathrm{L} 1$ & 0.70 & 9 & 2 & 2 & 2 & $>50$ \\
\hline $\mathrm{L} 2$ & 0.54 & 24 & 2 & 2 & 2 & $>50$ \\
\hline $\mathrm{L} 3$ & 0.69 & 50 & 2 & 2 & 2 & $>50$ \\
\hline L4 & 1.35 & 85 & 2 & 2 & 2 & $>50$ \\
\hline L5 & 10.82 & 120 & 2 & 2 & 2 & $>50$ \\
\hline
\end{tabular}

$\mathrm{x}$-ray diffractometry (HR-XRD) measuring reciprocal space maps near the (10-15) AlN reflex. ${ }^{16,17}$ The resistivity of the samples was determined by contactless (eddy current) resistivity measurements in a Delcom system. Impurity concentrations ( $\mathrm{Si}, \mathrm{C}, \mathrm{O}$, and $\mathrm{H}$ ) have been determined by secondary ion mass spectrometry (SIMS) by Evans Analytical group (the notation [] is used in this paper to denote the concentration obtained from SIMS).

The sample details are given in Table I. The sample series H1-5 ( $\mathrm{H}$ for the high $\mathrm{C}$ content and high growth rate) was grown at $1070^{\circ} \mathrm{C}$ at a reactor pressure of $50 \mathrm{mbar}$, a total flow of $8 \mathrm{slm}$, a TMAl (trimethyl aluminum) partial pressure of 4.3 Pa, a TMGa (trimethyl gallium) partial pressure of $0.5 \mathrm{~Pa}$, and a $\mathrm{NH}_{3}$ partial pressure of $940 \mathrm{~Pa}$ with $\mathrm{H}$ as the carrier gas. This results in a V/III ratio of 200 and a growth rate of $11.5 \mu \mathrm{m} / \mathrm{h}$. The $\mathrm{SiH}_{4} / \mathrm{III}$ ratio is varied between $6.3 \times 10^{-5}$ and $4.0 \times 10^{-4}$, resulting in Si concentrations between $1.1 \times 10^{18} \mathrm{~cm}^{-3}$ and $7 \times 10^{18} \mathrm{~cm}^{-3}$. The sample series L1-L5 (L for the low C content and low growth rate) is grown at $1070{ }^{\circ} \mathrm{C}$ at a reactor pressure of $200 \mathrm{mbar}$, a total flow of $8 \mathrm{slm} \mathrm{H}$, a TMAl partial pressure of $4.9 \mathrm{~Pa}$, a TMGa partial pressure of $0.35 \mathrm{~Pa}$, and a $\mathrm{NH}_{3}$ partial pressure of $3750 \mathrm{~Pa}$. This results in a V/III ratio of 700 and a growth rate of $1.6 \mu \mathrm{m} / \mathrm{h}$. The $\mathrm{SiH}_{4} / \mathrm{III}$ ratio is varied between $2.9 \times 10^{-5}$ and $2.8 \times 10^{-4}$, resulting in a Si concentration between $9 \times 10^{17} \mathrm{~cm}^{-3}$ and $1.2 \times 10^{19} \mathrm{~cm}^{-3}$.

We recorded the Doppler broadening of the positron-electron annihilation radiation with a variable-energy positron beam equipped with high purity germanium (HPGe) detectors with an energy resolution of $1.25 \mathrm{keV}$. Typically, $10^{6}$ counts were collected to the $511 \mathrm{keV}$ annihilation line. Conventional $S$ and $W$ parameters were determined at room temperature in all the samples and at $300-600 \mathrm{~K}$ in selected samples. The $S$ parameter is defined as the fraction of counts around the $<0.96 \mathrm{keV}$-wide $(0.4$ a.u.) central region of the peak. The $W$ parameter is the fraction of counts in the tail of the peak in the energy range of $\pm(3.00-7.60 \mathrm{keV})(1.6-4.0$ a.u.) from the center. For a detailed description of positron annihilation experiments and data analysis, the reader is referred to Refs. 12, 18, and 19.

Figure 1 shows the $S$ parameter as a function of positron implantation energy and corresponding mean implantation depth in selected MOVPE Si-doped AlGaN samples measured at room temperature. The characteristic $S$ parameter of the Mg-doped GaN reference where positrons only annihilate in the free state in the lattice is marked with the dashed line. ${ }^{20}$ The $S$ parameter decreases from its initial surface value at low energies of $0-4 \mathrm{keV}$ with increasing energy to the value of the Si-doped $\mathrm{Al}_{0.90} \mathrm{Ga}_{0.10} \mathrm{~N}$ layer, where it is almost constant in the range of $6-15 \mathrm{keV}$. This spread of energies corresponds to the thicknesses of the layers. At energies above $15 \mathrm{keV}$, the $S$ parameter gradually approaches the substrate specific value. The inset in Fig. 1 demonstrates the characteristic annihilation $S$ parameter of the layer region as a function of measurement temperature in the selected samples. The $W$ parameter (not shown) behaves in a similar but mirrorlike manner.

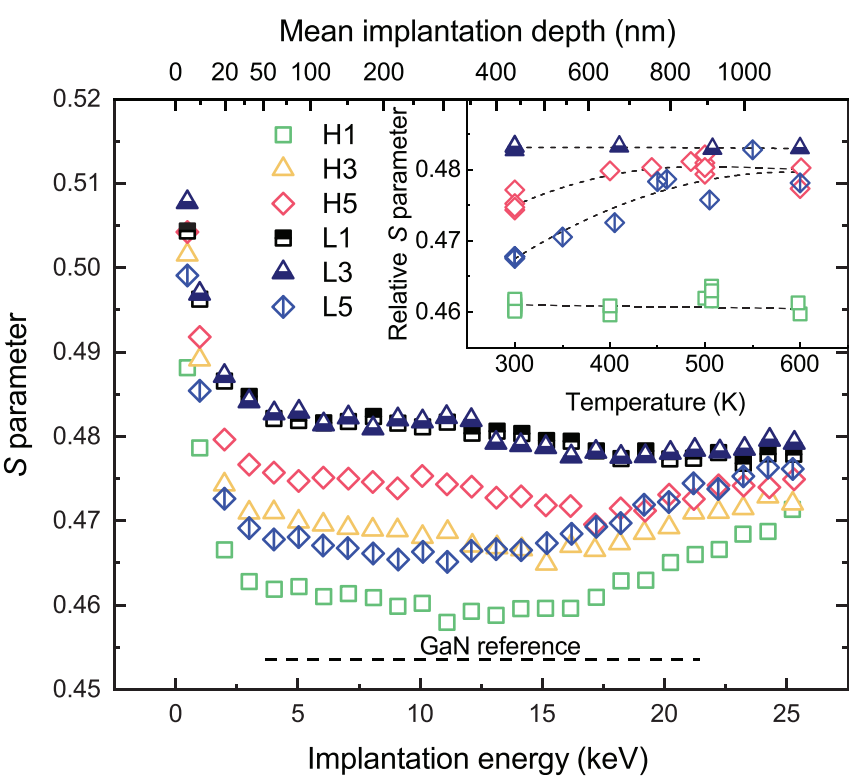

FIG. 1. The $S$ parameter as a function of positron implantation energy and corresponding mean implantation depth in selected MOVPE Si-doped AIGaN alloys measured at room temperature. The characteristic $S$ parameter of the Mg-doped $\mathrm{GaN}$ reference ${ }^{20}$ is marked with the dashed line. Inset: the characteristic $S$ parameter of the layer region as a function of measurement temperature in selected samples. The dashed lines are guides to the eye. 


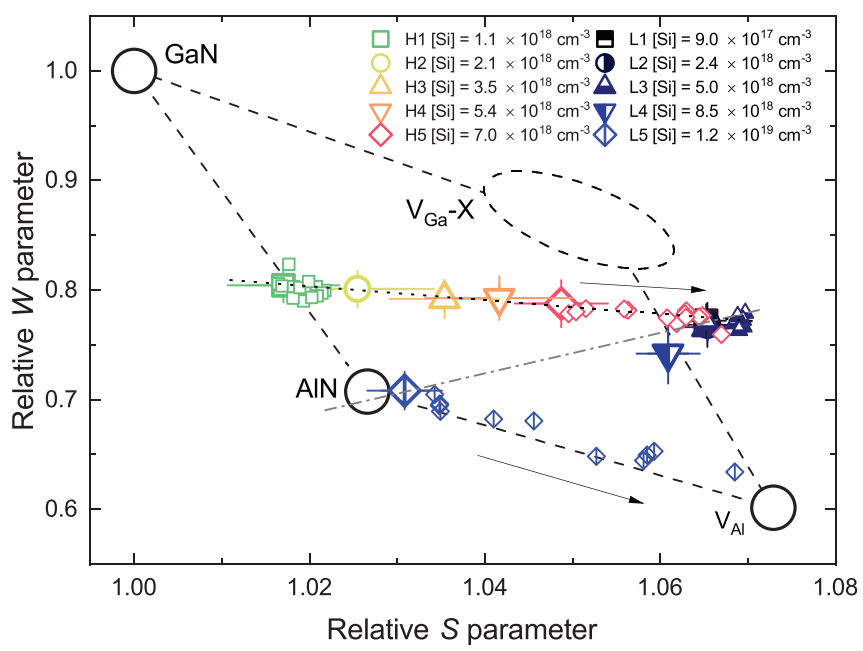

FIG. 2. Relative $S$ and $W$ parameters measured in MOVPE Si-doped AIGaN alloys. Big open circles mark the values for the bulk GaN, bulk AIN, and $V_{A 1}$ in AIN, respectively. The dashed oval marks the region of the $(S, W)$ parameters for ingrown $\mathrm{V}_{\mathrm{Ga}}$ complexed with $\mathrm{H}$ and $\mathrm{O}$ impurities or $\mathrm{V}_{N}$ in $\mathrm{GaN}$. Room temperature data have larger markers and error bars. Temperature-dependent data are shown with markers of smaller size; the error bars are omitted to simplify the visual appearance to the reader. Arrows indicate the trend of changing annihilation parameters as a response to increasing temperature from $300 \mathrm{~K}$ to $600 \mathrm{~K}$. The dashed lines connect the bulk and vacancy points in GaN and AIN, while the dotted and dashed-dotted lines illustrate the trends in the AIGaN data.

Figure 2 shows the $(S, W)$ parameters characterizing all the $\mathrm{AlGaN}$ layers, obtained by averaging over the parameter values in the $6-15 \mathrm{keV}$ range (exact range chosen separately for each sample due to the different layer thicknesses). In the so-called $S-W$ plot, different annihilation states are characterized by specific points in the $S-W$ plane. In the case of two competing states, e.g., the lattice state and the trapped state at a $\mathrm{Ga}$ vacancy in $\mathrm{GaN}$, the $S-W$ data form a straight line for a set of samples where the relative amounts of these annihilation states change from sample to sample. The data are shown as normalized by the value obtained in the $\mathrm{GaN}$ reference sample. Characteristic points representing the GaN lattice, AlN lattice, $\mathrm{V}_{\mathrm{A} 1}$ in $\mathrm{AlN}$, and the typical in-grown $\mathrm{Ga}$ vacancies in $\mathrm{GaN}$ (denoted by $\mathrm{V}_{\mathrm{Ga}^{-}}$ $\mathrm{X})$ are also shown. ${ }^{10,20,21}$ All the measured $(S, W)$ data fall inside the area defined by these four points. This suggests that the data measured in the AlGaN samples can be analyzed as the AlGaN alloy and corresponding cation vacancy defects. The fact that the $(S, W)$ data measured in samples H1-H5 and L1-L3 form a straight line indicates that these eight samples contain two (and only two) distinct states in which the positrons annihilate. At the left end, the $(S, W)$ data fall close to the line connecting $\mathrm{GaN}$ and $\mathrm{AlN}$ lattice values. We, hence, interpret the sample $\mathrm{H} 1(S=1.02, W=0.80)$ to represent the AlGaN alloy lattice in this sample set. At the right end of the line, samples L1-L3 are clustered, close to the line connecting $\mathrm{V}_{\mathrm{Ga}} \mathrm{X}$ in $\mathrm{GaN}$ and $\mathrm{V}_{\mathrm{A} 1}$ in AlN. These data are interpreted as saturation of positron trapping at the group III (cation) vacancy defects $\left(\mathrm{V}_{\mathrm{III}}\right)$ present in most of the $\mathrm{AlGaN}$ samples studied in this work. Note that there is a trend-like shift of the $(S, W)$ parameters towards the vacancy-like data in the $\mathrm{H}$ series samples, indicating an increase in the cation vacancy concentration with increasing Si doping. This trend is similar to what has been observed previously in Si-doped $\mathrm{AlGaN}$ with $60 \% \mathrm{Al},{ }^{22}$ while generally from the point of view of electrical compensation, Si doping has not been found to induce high concentrations of cation vacancies in $\mathrm{GaN}$ or AlGaN up to $65 \% \mathrm{Al}$ content. ${ }^{20,22-26}$

It is known that in $\mathrm{GaN},{ }^{8,27}$ and particularly in $\mathrm{AlN},{ }^{10}$ negative non-open volume defects (negative ions) can effectively trap positrons also at room temperature due the relatively high binding energy of this shallow trap. Trapping at these negative ions produces $(S, W)$ parameters of the lattice and limits the effect of the trapping to cation vacancies on the annihilation parameters. At elevated temperatures, positrons escape the negative ion-induced traps. Hence, in order to reliably estimate the $\mathrm{V}_{\mathrm{III}}$ concentrations, we measured the $(S, W)$ parameters in selected samples also in the temperature range of $300-600 \mathrm{~K}$ at a positron implantation energy of $6 \mathrm{keV}$. The results of the temperature-dependent Doppler broadening measurements are shown in the inset of Fig. 1 and in Fig. 2 (small markers with temperature as the running parameter; arrows show the trend with increasing temperature). There is essentially no change in the $(S, W)$ parameters in samples $\mathrm{H} 1$ and $\mathrm{L} 3$, which agrees with $\mathrm{H} 1$ representing the AlGaN lattice and $\mathrm{L} 3$ representing the saturation trapping to AlGaN-specific $\mathrm{V}_{\text {III. }}$ In sample $\mathrm{H} 5$, the $(S, W)$ parameters move towards this $\mathrm{V}_{\text {III }}$ point with increasing temperature, saturating at $500 \mathrm{~K}$. This is a clear sign of the presence of negative ions in concentrations comparable to the vacancies in sample $\mathrm{H} 5$.

The concentrations of the cation vacancies and negative ion type defects in the studied samples can be estimated from the dependence of the $S(W)$ parameter on the trapping rates to these defects. The measured $S$ parameter can be expressed as ${ }^{12}$

$$
S=\frac{\tau_{B}^{-1}}{\tau_{B}^{-1}+\sum_{i} \kappa_{D, i}} S_{B}+\sum_{i} \frac{\kappa_{D, i}}{\tau_{B}^{-1}+\sum_{i} \kappa_{D, i}} S_{D, i},
$$

where $\tau_{B}$ and $S_{B}$ are the positron lifetime and $S$ parameter characterizing the AlGaN lattice, respectively, $S_{D, i}$ and $\kappa_{D, i}$ are the defectcharacteristic $S$ parameter and trapping rate, and the sum is taken over all the defects detected with positrons. Negative ions produce the same annihilation parameters as the lattice, and we assume that the AlGaN lattice has a free positron lifetime close to those of GaN and AlN and assign $\tau_{B}=160$ ps. ${ }^{8,10}$ The trapping rate $\kappa_{D}$ of a positron at a defect $D$ is proportional to its concentration $c_{D}$ as $\kappa_{D}=\mu_{D} c_{D}$, where $\mu_{D}$ is the trapping coefficient at this defect. ${ }^{18,19}$ For a negatively charged vacancy in nitrides, the trapping coefficient at $300 \mathrm{~K}$ is $\mu_{D}=3 \times 10^{15} \mathrm{~s}^{-1}$ and exhibits a $T^{-1 / 2}$ dependence on the temperature. ${ }^{12}$ Hence, an increase in the trapping rate with decreasing temperature is an experimental fingerprint of a negative vacancy. The trapping coefficient at negative ions $\mu_{i o n}$ is the same as for negative vacancies, but the positrons can escape the shallow trap created by the negative ion at elevated temperatures. In AlN, the binding energy to negative ions has been observed to be more than $150 \mathrm{meV}$, making the escape efficient only at temperatures above $300 \mathrm{~K}^{10}$

The temperature-dependent data obtained in sample H5, analyzed with Eq. (1), correspond to a negative cation vacancy concentration of $2 \times 10^{18} \mathrm{~cm}^{-3}$ and a negative ion concentration of $1-2 \times 10^{18} \mathrm{~cm}^{-3}$. This coincides with the $\mathrm{C}$ content in the $\mathrm{H}$ series (see Table I), allowing us to conclude that $\mathrm{C}$ is in the negative (acceptor) charge state. Assuming this holds for the whole series $\mathrm{H} 1-\mathrm{H} 5$, we can estimate the negative cation vacancy concentrations $\left[\mathrm{V}_{\text {III }}\right]$ in all 
the $\mathrm{H}$ series samples from the combined temperature-dependent and room-temperature data as ranging from $<1 \times 10^{16} \mathrm{~cm}^{-3}$ (H1) to $2 \times 10^{18} \mathrm{~cm}^{-3}(\mathrm{H} 5)$. All the estimated values are shown in Table I. The lack of the temperature dependence of the $(S, W)$ parameters in sample L3 is consistent with the $\mathrm{C}$ content being 10 times lower than in the $\mathrm{H}$ series and with the saturation trapping of positrons at cation vacancy defects. Together, these allow us to estimate that $\left[\mathrm{V}_{\mathrm{III}}\right]$ $\geq 5 \times 10^{18} \mathrm{~cm}^{-3}$ in samples L1-L3 (and L4). Sample L5 is a clear outlier in the whole set, and the $(S, W)$ parameters at room temperature are very close to the AlN point and shift with increasing temperature all the way to the $\mathrm{V}_{\mathrm{A} 1}$ point.

Following the results listed in Table I, the role of the cation vacancies in the electrical compensation of the $n$-type doping strongly depends on the growth conditions and impurity content of the samples. For the $\mathrm{H}$ series with a high $\mathrm{C}$ content $\left(2 \times 10^{18} \mathrm{~cm}^{-3}\right),\left[\mathrm{V}_{\mathrm{III}}\right]$ $<[\mathrm{C}]$ at Si doping levels below $5 \times 10^{18} \mathrm{~cm}^{-3}$. Even as the cation vacancies are negatively charged in the $\mathrm{H}$ series samples, any electrical compensation is dominated by $\mathrm{C}$ acting as the acceptor, resulting in high resistivity in samples $\mathrm{H} 1-\mathrm{H} 3$ as [Si] is only slightly higher than $[\mathrm{C}]+\left[\mathrm{V}_{\mathrm{III}}\right]$. At higher Si doping levels $(\mathrm{H} 4$ and $\mathrm{H} 5)\left[\mathrm{V}_{\mathrm{III}}\right] \approx[\mathrm{C}]$, cation vacancies and $\mathrm{C}$ contribute equally to the electrical compensation. However, in these samples, [Si] is significantly higher than [C] $+\left[\mathrm{V}_{\mathrm{III}}\right]$, resulting in a low-resistivity material. In the $\mathrm{L}$ series with a low $\mathrm{C}$ content $\left(2 \times 10^{17} \mathrm{~cm}^{-3}\right)$, [Si] $\gg[\mathrm{C}]$ for all the samples and the $\mathrm{V}_{\mathrm{III}}$ concentration exceeds $5 \times 10^{18} \mathrm{~cm}^{-3}$ for the entire sample series. Interestingly, the electrical resistivity remains low up to a Si concentration of about $5 \times 10^{18} \mathrm{~cm}^{-3}$ (samples L1-L3) and then strongly increases with a further increase in the $\mathrm{Si}$ concentration. Note that the lowest resistivity of all the studied samples is found in L2 even though the $\mathrm{Si}$ concentration is only $30 \%$ of that in the sample $\mathrm{H} 5$ (lowest resistivity of the $\mathrm{H}$ series). The results from samples L1-L3 imply that the cation vacancies are not involved in the electrical compensation and that they are part of neutral complexes that do not involve Si since it would be compensated. Interestingly, this is opposite to what has been suggested in $\mathrm{AlN}^{28}$ As the positron data are in saturation to the vacancies in these samples, we cannot exclude the possibility that a fraction of the cation vacancies are in the negative charge state. However, this fraction must be low as the electrical characteristics imply that the total acceptor concentrations in samples L1-L3 need to be an order of magnitude lower than in samples $\mathrm{H} 1-\mathrm{H} 3$.

The singular behavior of sample L5 in the $(S, W)$ plot of Fig. 2 provides a potential explanation for the sudden increase in electrical compensation in samples L4 and L5 where the Si concentration is above $5 \times 10^{18} \mathrm{~cm}^{-3}$. Fitting the temperature-dependent trapping model for L5 results in a neutral vacancy and negative ion concentrations $>5 \times 10^{18} \mathrm{~cm}^{-3}$ (for both). Note that the negative ion concentration in L5 is higher than that of any of the negatively charged defects in the $\mathrm{H}$ series samples, even when added together. $\mathrm{Si}$ in the negative DX configuration would explain this result as $\mathrm{Si}$ is the only impurity with a sufficient concentration. Si DX centers are predicted to exist only in $\mathrm{AlN}^{29}$ and have been experimentally observed in $\mathrm{AlGaN}$ at $\mathrm{Al}$ fractions as low as $80 \%{ }^{6,7}$ We suggest that the electrical compensation emerging at a high Si concentrations in the L series is dominated by this phenomenon. The positron data suggest the presence of this effect also in sample L4 but much less pronounced. The fact that the room temperature data in sample L5 strongly resemble AlN suggests that the Si DX centers are mainly formed in naturally occurring Al-rich regions of the AlGaN alloy. Further studies are required for a detailed quantitative analysis. Interestingly, the high temperature data in sample L5 also resemble $\mathrm{AlN}\left(\mathrm{V}_{\mathrm{A1}}\right)$, suggesting that the high Si content may cause the cation vacancies to form preferentially in the Al-rich regions as well. Note that $\mathrm{V}_{N}$ are predicted to exhibit a negative charge state at the Fermi level close to the conduction band in AlN and could, in principle, act as negative ions, ${ }^{11}$ but their formation enthalpy is high, especially in $\mathrm{N}$-rich growth conditions. The $\mathrm{L}$ series is grown at a high V/III ratio, and hence it is likely that the neutral $\mathrm{V}_{\text {III }}$ complexes in the $\mathrm{L}$ series do not involve $\mathrm{V}_{N}$ either. It should also be noted that considering thermodynamics-driven formation of point defects is appropriate in these samples, as our data show that (i) cation vacancy concentrations increase with Si doping (Fermi level) in the $\mathrm{H}$ series samples and (ii) the overall cation vacancy concentrations are lower in $\mathrm{H}$ series (low V/III ratio) than in L series (high V/III ratio).

Finally, we note that in Fig. 2, the point describing the lattice of the AlGaN alloy is closer to GaN than could be expected assuming linear interpolation ("Vegard's law") in $\mathrm{AlGaN}$ with a 90\% $\mathrm{Al}$ content. Some preference to GaN-like over AlN-like behavior is expected as $\mathrm{Ga}$ has $103 d$ electrons as the outermost core and $\mathrm{Al}$ has $62 p$ electrons in the wurtzite lattice. In addition, the positron affinity ${ }^{30}$ of $\mathrm{GaN}$ is slightly higher than that of AlN, suggesting that Ga-rich regions in the alloy could be more attractive to positrons similar to that observed in InGaN. ${ }^{31}$ Furthermore, the vacancy point (samples H5, L1-L3) is clearly closer to $\mathrm{V}_{\mathrm{Ga}}$ than $\mathrm{V}_{\mathrm{Al}}$. Theoretical calculations predict that the formation enthalpy $V_{G a}$ in $G a N$ is lower (by $1-2 \mathrm{eV}$ ) than $V_{A 1}$ in $\mathrm{AlN},{ }^{9,11}$ which suggests that cation vacancies could strongly prefer Ga-rich regions in the alloy. The atomic configuration of the second nearest neighbor shell for the $\mathrm{V}_{\mathrm{III}}$ has been shown to be sufficient to produce an effect of this magnitude in InGaN. ${ }^{31}$ The statistical probability of a cation (vacancy) site having Ga atoms in more than half of its second nearest neighbor positions in a random AlGaN alloy with $90 \% \mathrm{Al}$ is less than $5 \times 10^{-5}$, corresponding to a site density of only $2.5 \times 10^{18} \mathrm{~cm}^{-3}$. It is tempting to interpret that the point defect formation affects the atomic level details of the alloy distribution.

In summary, we have used positron annihilation spectroscopy to study in-grown $\mathrm{V}_{\text {III }}$ cation vacancies in Si-doped $\mathrm{Al}_{0.90} \mathrm{Ga}_{0.10} \mathrm{~N}$ alloys grown by MOVPE. We show that the cation vacancy defects caused by the increase in the Fermi level due to the Si doping become important compensating centers at doping levels approaching $10^{19} \mathrm{~cm}^{-3}$ in material with a high $\mathrm{C}$ content (grown at a low V/III ratio). Interestingly, the cation vacancy defects that are present at relatively high concentrations do not appear to play a role in the compensation in material with a low $\mathrm{C}$ content (grown at a high V/III ratio). Instead, at the highest $\mathrm{Si}$ doping levels above $10^{19} \mathrm{~cm}^{-3}$, Si DX center formation appears to be the dominant compensation mechanism.

The authors wish to thank T. Heikkinen for help with AlN experiments and S. Hagedorn (FBH Berlin) for providing ELO AlN/sapphire. This work was partially funded by the Academy of Finland (Project No. 315082) and by the German Ministry of Science and Education (BMBF) within the "Advanced UV for Life" consortium.

\section{DATA AVAILABILITY}

The data that support the findings of this study are available from the corresponding author upon reasonable request. 


\section{REFERENCES}

${ }^{1}$ III-Nitride Ultraviolet Emitters, edited by M. Kneissl and J. Rass (Springer, 2016).

${ }^{2}$ M. Kneissl, T.-Y. Seong, J. Han, and H. Amano, Nat. Photonics 13, 233 (2019).

${ }^{3}$ F. Mehnke, L. Sulmoni, M. Guttmann, T. Wernicke, and M. Kneissl, Appl. Phys. Express 12, 012008 (2019).

${ }^{4}$ Y. Taniyasu, M. Kasu, and T. Makimoto, Appl. Phys. Lett. 84, 2115-2117 (2004).

${ }^{5}$ M. S. Brandt, R. Zeisel, S. T. B. Gönnenwein, M. W. Bayerl, and M. Stutzmann, Phys. Status Solidi B 235, 13 (2003).

${ }^{6} \mathrm{X}$. T. Trinh, D. Nilsson, I. G. Ivanov, E. Janzen, A. Kakanakova-Georgieva, and N. T. Son, Appl. Phys. Lett. 105, 162106 (2014).

${ }^{7}$ F. Mehnke, X. T. Trinh, H. Pingel, T. Wernicke, E. Janzén, N. T. Son, and M. Kneissl, J. Appl. Phys. 120, 145702 (2016).

${ }^{8}$ K. Saarinen, T. Laine, S. Kuisma, J. Nissilä, P. Hautojärvi, L. Dobrzynski, J. M. Baranowski, K. Pakula, R. Stepniewski, M. Wojdak, A. Wysmolek, T. Suski, M. Leszczynski, I. Grzegory, and S. Porowski, Phys. Rev. Lett. 79, 3030 (1997).

${ }^{9}$ J. L. Lyons and C. G. Van de Walle, npj Comput. Mater. 3, 12 (2017).

${ }^{10}$ J.-M. Mäki, I. Makkonen, F. Tuomisto, A. Karjalainen, S. Suihkonen, J. Räisänen, T. Y. Chemekova, and Y. N. Makarov, Phys. Rev. B 84, 081204 (2011).

"Q. Yan, A. Janotti, M. Scheffler, and C. G. Van de Walle, Appl. Phys. Lett. 105, 111104 (2014)

12F. Tuomisto and I. Makkonen, Rev. Mod. Phys. 85, 1583 (2013).

${ }^{13}$ G. Kusch, M. Nouf-Allehiani, F. Mehnke, C. Kuhn, P. R. Edwards, T. Wernicke, A. Knauer, V. Kueller, G. Naresh-Kumar, M. Weyers, M. Kneissl, C. Trager-Cowan, and R. W. Martin, Appl. Phys. Lett. 107, 072103 (2015).

${ }^{14} \mathrm{~J}$. Enslin, A. Knauer, A. Mogilatenko, F. Mehnke, M. Martens, C. Kuhn, T. Wernicke, M. Weyers, and M. Kneissl, Phys. Status Solidi A 216, 1900682 (2019).

${ }^{15}$ N. Susilo, E. Ziffer, S. Hagedorn, L. Cancellara, C. Netzel, N. L. Ploch, S. Wu, J. Rass, S. Walde, L. Sulmoni, M. Guttmann, T. Wernicke, M. Albrecht, M. Weyers, and M. Kneissl, Photonics Res. 8, 589 (2020).

${ }^{16} \mathrm{~F}$. Mehnke, T. Wernicke, H. Pingel, C. Kuhn, C. Riech, V. Kueller, A. Knauer, M. Lapeyrade, M. Weyers, and M. Kneissl, Appl. Phys. Lett. 103, 212109 (2013).
${ }^{17}$ G. Kusch, F. Mehnke, J. Enslin, P. R. Edwards, T. Wernicke, M. Kneissl, and R. W. Martin, Semicond. Sci. Technol. 32, 035020 (2017).

${ }^{18} \mathrm{~K}$. Saarinen, P. Hautojärvi, and C. Corbel, "Positron annihilation spectroscopy of defects in semiconductors," in Semiconductors and Semimetals, edited by M. Stavola (Elsevier, 1998), Vol. 51A, p. 209.

${ }^{19}$ R. Krause-Rehberg and H. S. Leipner, Positron Annihilation in Semiconductors: Defect Studies (Springer, 1999), Vol. 127.

${ }^{20}$ J. Oila, V. Ranki, J. Kivioja, K. Saarinen, P. Hautojärvi, J. Likonen, M. Baranowski, K. Pakula, T. Suski, M. Leszczynski, and I. Grzegory, Phys. Rev. B 63, 045205 (2001).

${ }^{21}$ F. Tuomisto, V. Prozheeva, I. Makkonen, T. H. Myers, M. Bockowski, and H. Teisseyre, Phys. Rev. Lett. 119, 196404 (2017).

${ }^{22}$ A. Uedono, K. Tenjinbayashi, T. Tsutsui, Y. Shimahara, H. Miyake, K. Hiramatsu, N. Oshima, R. Suzuki, and S. Ishibashi, J. Appl. Phys. 111, 013512 (2012).

${ }^{23}$ S. F. Chichibu, A. Uedono, T. Onuma, T. Sota, B. A. Haskell, S. P. DenBaars, J. S. Speck, and S. Nakamura, Appl. Phys. Lett. 86, 021914 (2005).

${ }^{24}$ J. Slotte, F. Tuomisto, K. Saarinen, C. G. Moe, S. Keller, and S. P. DenBaars, Appl. Phys. Lett. 90, 151908 (2007).

${ }^{25}$ S. F. Chichibu, H. Miyake, Y. Ishikawa, M. Tashiro, T. Ohtomo, K. Furusawa, K. Hazu, K. Hiramatsu, and A. Uedono, J. Appl. Phys. 113, 213506 (2013).

${ }^{26}$ V. Prozheeva, I. Makkonen, H. Li, S. Keller, U. K. Mishra, and F. Tuomisto, Phys. Rev. Appl. 13, 044034 (2020).

${ }^{27}$ F. Tuomisto, K. Saarinen, B. Lucznik, I. Grzegory, H. Teisseyre, T. Suski, S. Porowski, P. Hageman, and J. Likonen, Appl. Phys. Lett. 86, 031915 (2005).

${ }^{28}$ J. S. Harris, J. N. Baker, B. E. Gaddy, I. Bryan, Z. Bryan, K. J. Mirrielees, P. Reddy, R. Collazo, Z. Sitar, and D. L. Irving, Appl. Phys. Lett. 112, 152101 (2018).

${ }^{29}$ L. Gordon, J. L. Lyons, A. Janotti, and C. G. V. de Walle, Phys. Rev. B 89, 085204 (2014).

${ }^{30}$ I. Makkonen, A. Snicker, M. Puska, J.-M. Mäki, and F. Tuomisto, Phys. Rev. B 82, 041307 (2010).

${ }^{31}$ V. Prozheeva, I. Makkonen, R. Cuscó, L. Artús, A. Dadgar, F. Plazaola, and F. Tuomisto, Appl. Phys. Lett. 110, 132104 (2017). 